IP Periodica Polytechnica

Transportation Engineering

46(2), pp. 63-68, 2018

https://doi.org/10.3311/PPtr.11565

Creative Commons Attribution (i)

RESEARCH ARTICLE

\section{Experimental Studies of Different Strength Steels MIG Brazed Joints}

\author{
${\text { Miklós Berczeli }{ }^{1 *}, Z^{2} \text { oltán Weltsch }}^{1,2}$
}

Received 11 March 2017; accepted 05 October 2017

\begin{abstract}
Nowadays the stakeholders of vehicle industry are focusing on making materials and technologies for motor-vehicle bodies that satisfy the newest requirements. Reduction of the manufactured vehicle's dead load - while the important material properties of proper functioning only change in a small degree - is such a requirement. There exist many solutions to satisfy this requirement. One of them is when the materials are in the same group, but the material with higher strength is used with less thickness. Reducing mass should be searched in recent high strength steels. Evidently, to reduce dead load, manufacturers use steels with different strength, depending on the function of the given structural component. The advantages of steels with increased strength is the reduced cost of manufacturing and to make the hybrid material couplings cheaper as well. However, malleability is one of the key issues of manufacturing body components, so common use of basic and increased strength steels is necessary. The connection between the standard (DC) and increased strength (DP) steels design is one way for the binding established by brazing, which has several advantages over welding. In this paper MIG brazing is formed between the DC-DP steel pairs and examine changes in the surface properties and the interfacial layer. The results shows there are differences between the DC and DP side of the joint.
\end{abstract}

\section{Keywords}

Brazing, DP 600, DC 01, high strength steel, wetting

\footnotetext{
${ }^{1}$ Department of Automotive Technologies,

Faculty of Transportation Engineering and Vehicle Engineering,

Budapest University of Technology and Economics,

H-1521 Budapest, P.O.B. 91, Hungary

${ }^{2}$ Department of Materials Technology,

Faculty of Mechanical Engineering and Automation,

Pallasz Athéné University,

H-6000 Kecskemét, Izsáki út 10., Hungary

*Corresponding author, e-mail: berczeli.miklos@gmail.com
}

\section{Introduction}

The automotive industry has certainly begun to show signs of rebounding from the economic downturn; however, companies are now being asked to "do more with less" as production volumes approach the levels of several years ago. More than ever, companies require operational efficiencies to maintain process flow and avoid unscheduled downtime of automated equipment. Over the decades, harmful vehicular emissions have shown a negative impact on the environment and human health. The increasing air pollution from the transportation sector has led many government agencies to lay strict regulations on the automobile manufacturers to curb the harmful emissions under permissible limits (Budai and Tiszai, 2015).

One such example is the European agency, which has set mandatory emission reduction targets for automakers in Europe. According to EU rules, the fleet average by cars to be achieved by 2021 must be 95 grams of $\mathrm{CO}_{2} /$ kilometer, which works out to a fuel consumption rate of around 4.1 liter $/ 100 \mathrm{~km}$ of petrol or 3.6 liter/100 km of diesel (Joeri et al., 2013). Stringent regulations and heavy penalties imposed by government agencies have put immense pressure on automakers to scout different methods and technologies that help curb vehicular emissions (Malte et al., 2009).

For this reason, the steel industry has developed strip steel grades with suitable properties, as required for meeting the demands placed on the automotive manufacturers. One of these steel grades is the Dual Phase (DP) steels, which is thought to offer solutions for critical crash component criteria. (Ghosh and Ray, 2017)

The manufacturers are using different types of steels in the body, depending on what the function of the structural element. The following figure shows a recent motor-vehicle body with the used types of steels and their integration spots (Fig. 1). The red parts shows the high strength steels and the blue parts shows the low strength steels in the vehicle body. Where they need higher strength and stiffness, because of the safety, they use high ultimate strength steels, for example DP 600. 


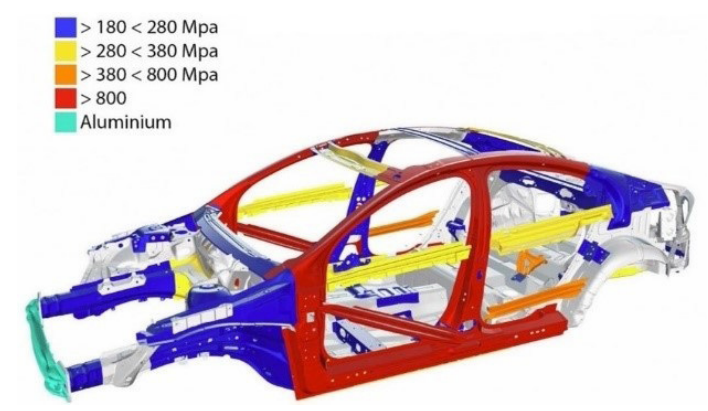

Fig. 1 A modern vehicle body with the used types of steels (Volvo)

In case of accident, where the deformation and the energy absorption is the important, they use lower strength, generally used non-alloyed DC steels (Oliver et al., 2007).

Automotive dual phase strip steel grades are usually produced via cold rolling and continuous annealing processing routes. The DP 600 steel consisting of a ferrite matrix containing a hard second phase usually islands of martensite. These have high yield strength and good formability, it allows to reduce the thickness of the wall and the vehicle body weight (Cardoso and Moreira, 2015).

The DC steels are cold rolled non-alloy low carbon mild steels for cold-forming. The typical applications in the vehicle industry are the die forming, small and medium scale deep drawing (Michael, 2007). The advantages of steels with increased strength is the reduced cost of manufacturing and to make the hybrid material couplings cheaper as well.

Although increasing strength reduces the malleability of the materials. However, malleability is one of the key issues of manufacturing body components, so common use of basic and increased strength steels is necessary. Without developing manufacturing technologies, it can not be possible, that is why the joint technology should adapt to the recent, hybrid combinations of materials. DP and DC steels could be bonding with rivets, bolts and welding (Kalácska et al., 2017), but a new innovative technology could be if we join the materials with brazing (Sushovan et al., 2016; Májlinger et al., 2013). Brazing is indirect, diffusive, optionally solvent joints, such that are used on components which are made of metal or non metal, but in this case the components are coated with metal. The joint is made with metallic substrate during adhesive and diffusive process. Due to this, the joint can be made without thaw of the material. Here are the advantages: the usable components can be joined without significant changes in shape, inner stresses and warps caused by undesirable changes in texture can be avoided, it is easy to automate (Pickin, 2007).

The brazing process is a variant of the MIG/MAG welding process, where the majority of the process-essential variables are identical to conventional MIG/MAG welding processes. However, in the braze welding process, the melting point of the filler wires is significantly lower with relation to the melting point of the parent material. During the arc welding process, the filler wire melts at temperatures typically over $1600^{\circ} \mathrm{C}$, whereas for brazing the wire melts at less than $1000^{\circ} \mathrm{C}$ (Sushovan et al., 2013).

As in the standard MIG/MAG welding process, a continuously fed wire electrode is melted by an arc formed between the electrode and the work piece, but no significant melting or fusion of the parent metal occurs because of the lower temperature. The molten metal flows into the gap between the parts to be joined and solidifies after wetting either across or between the surfaces via capillary action to form the solid joint. There are several advantages provided by the braze filler metals used. They are often corrosion resistant, resulting in a better overall joint corrosion resistance as compared to the parent materials and their low hardness means that any necessary post-joining machining can be significantly easier. It is also unnecessary to use a flux with these filler metals, unlike in more traditional flame or furnace brazing. It is also necessary to achieve a very good joint fit-up when attempting to braze butt or fillet joints, to ensure the correct wetting and penetration (Sushovan et al., 2016).

Wetting, in general, is the interaction of a liquid phase with a solid phase when surrounded by a gas phase or a second liquid phase. There are many common examples of wetting phenomena, such as the spreading of a liquid over a surface. The interfaces which are produced can be solid/liquid, solid/gas or solid/liquid, liquid/gas or liquid/liquid. Wettability is most often described by the geometry of a sessile or resting drop (Hlinka and Weltsch, 2013). Contact angle $(\theta)$ is a measure of wettability and is defined as the angle between the surfaces of the liquid and the solid substrate at the line of contact, as measured from the side of the liquid. A low contact angle means high wettability and a high contact angle means poor wettability. Wetting behaviors are important in the vehicle industry and the development (Dezso and Kaptay, 2017). A lot of paper deals with the modification of surface properties to increase the surface energy (decrease the contact angle to the way of hydrophilic), with these techniques the quality of the joints can be improved. The surface modification could be a laser beam treatment (Hlinka et al., 2017; Verezub et al., 2011). In this study the contact angle represent the quality of the connection between the copper filler wire and the DP, DC steels.

Our goal is to make hybrid joints with MIG brazing using DP 600 and DC 01 steels. For this it have to be investigated the effect of the different MIG brazing parameters and the different pairing of steels. We measured the contact angle between the copper based filler wire and the base materials, the microhardness and the tensile strength of the brazed joints.

\section{Experimental procedure}

The materials for the present investigation are zinc-coated DP 600 and un-coated DC 01 steels of $1.2 \mathrm{~mm}$ thicknesses. The chemical composition and mechanical properties of base metals are shown in Table 1. 
Table 1 Chemical composition and mechanical properties of the base materials

\begin{tabular}{|c|c|c|c|c|c|c|c|c|}
\hline \multicolumn{9}{|c|}{ DP 600 steel } \\
\hline $\mathrm{Fe}(\mathrm{m} \%)$ & $\mathrm{C}(\mathrm{m} \%)$ & $\mathrm{Si}(\mathrm{m} \%)$ & $\operatorname{Mn}(m \%)$ & $\mathrm{Cr} \mathrm{m}(\%)$ & $\mathrm{Ni}(\mathrm{m} \%)$ & $\mathrm{Ni}(\mathrm{m} \%)$ & Hardness (HV) & Ultimate Tensilse Strength $(\mathrm{kN})$ \\
\hline 97.5 & 0.09 & 0.009 & 1.8 & 0.2 & 0.02 & 0.02 & 230 & 15 \\
\hline \multicolumn{9}{|c|}{ DC 01 steel } \\
\hline $\mathrm{Fe}(\mathrm{m} \%)$ & $\mathrm{C}(\mathrm{m} \%)$ & $\mathrm{Si}(\mathrm{m} \%)$ & $\operatorname{Mn}(\mathrm{m} \%)$ & $\mathrm{Cr}(\mathrm{m} \%)$ & $\mathrm{Ni}(\mathrm{m} \%)$ & $\mathrm{Al}(\mathrm{m} \%)$ & Hardness (HV) & Ultimate Tensilse Strength $(\mathrm{kN})$ \\
\hline 99.5 & 0.025 & 0.018 & 0.23 & 0.013 & 0.01 & 0.04 & 127 & 7.4 \\
\hline
\end{tabular}

The plates were mechanically sectioned to avoid heat input, into $50 \times 160 \mathrm{~mm}$ plates. Before the brazing process the edges of the steels sheets were grinded and degreased by acetone to avoid any rust, dirt or grease. The MIG brazing of the butt joint was performed using a Migatronic Flex 3000 machine and diameter of $1.2 \mathrm{~mm}$ of copper based $\mathrm{CuSi} 3$ filler wire. The feed rate was $650 \mathrm{~mm} / \mathrm{min}$ by using linear mechanical feeding. Butt joints were made with $0.4 \mathrm{~mm}$ gap between the DP and DC sheets. Argon gas was used as shielding gas to protect the joint from oxidation and cool during the brazing with the flow rate of 14 1/min. During brazing, the torch was maintained at $90^{\circ}$ travel and working angle. The Fig. 2 shows the experimental setup.

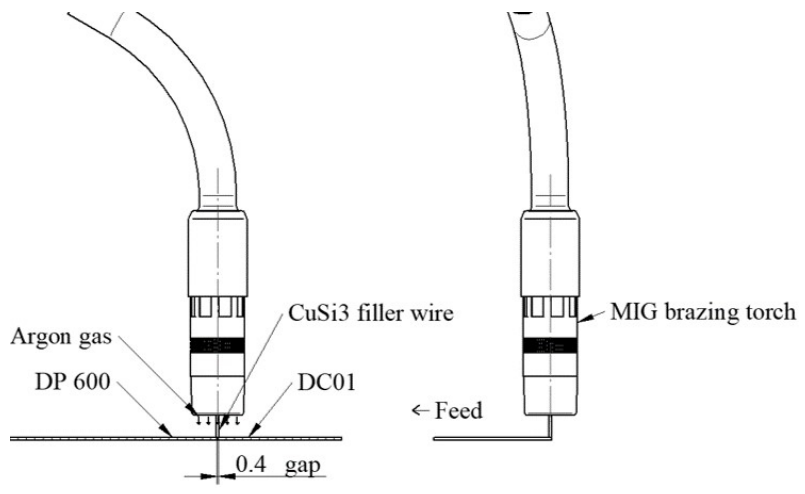

Fig. 2 The experimental setup

Three different pairing of joints MIG brazed joints were made: DP 600-DP 600, DC 01-DC 01 and the mixed DP 600-DC 01.

In order to analyze the microhardness profile of the MIG brazed joints near the surface and the contact angle between the filler wire and steels, the specimens were cross sectioned with a cutting machine using diamond-rimmed cutting blade. The section specimens were mounted with EPO Moulding Compound then, subsequently, grinded with $\mathrm{SiC}$ paper and polished with diamond suspension to $1 \mu \mathrm{m}$. The contact angle was measured with software based on the optical microscope pictures. The microhardness test was performed with a Wilson Wolper 401 standard Vicker's microhardness testing machine, the indenter testing force was $0.1 \mathrm{~N}$ and the penetration time $12 \mathrm{sec}$.

The butt joints samples were machined to prepare standard tensile test specimens. Shear tensile test were carried out in a INSTRON 5900R testing machine at a cross-head speed of $30 \mathrm{~mm} / \mathrm{min}$. Five samples were tested for each pairing of MIG brazed to evaluate the joint strength.

\section{Results}

\subsection{Wettability measurement}

After the MIG brazing of the hybrid DP-DC steels optical microscope measurement were performed to determine the behaviour of the brazed joints, the Fig. 3. cross section shows the hybrid joint conditions.

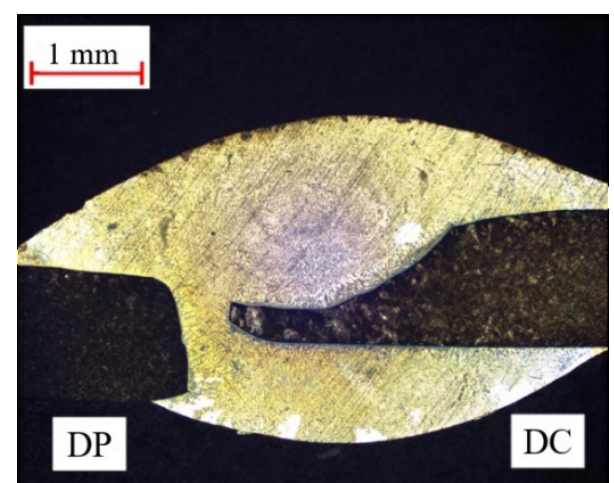

Fig. 3 Microscopic picture of cross section of brazed DP 600-DC 01 joints

The centre line of the CuSi3 brazing shifted in direction of the DC 01 steel, it is because of the wettability of the different steels. The DP 600 steel has zinc coating. During the MIG brazing the $\mathrm{CuSi} 3$ filler wire melted in the $0.4 \mathrm{~mm}$ gap, spread on the butt side of the sheets and damaged the coating on both side of the steel. This surface property changing has negative effects to the CuSi3 wetting behaviour.

Fig. 4 shows the contact angle on the top of the between the DP 600 steel and CuSi3 filler wire, it was $60^{\circ}$. The contact angle should be measured when the filler wire is melted during the brazing method, our previous studies shows that the value of contact angle has only little difference between the melted and the solid state of wire.

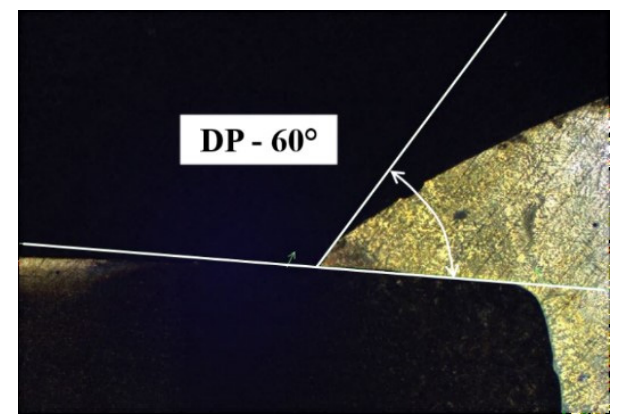

Fig. 4 Contact angle measurement between CuSi3 filler wire and DP 600 
The contact angle between DC 01 steel and $\mathrm{CuSi} 3$ wire was $30^{\circ}$ (Fig. 5).

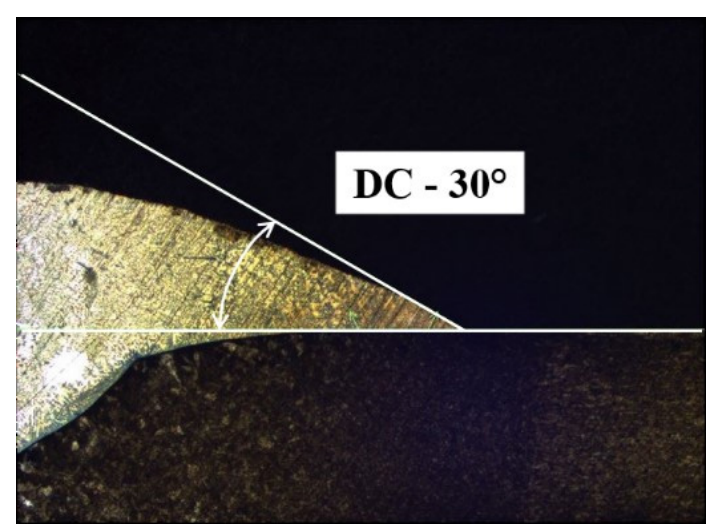

Fig. 5 Contact angle measurement between $\mathrm{CuSi} 3$ filler wire and DC 01

The contact angle shows, that the joint quality is better on the DC 01 steel side. These behaviours and the damage of the zinc coating need to be considered during the technology planning. Removing or pre-heat treating method of the coating could increase the wettability between the $\mathrm{CuSi} 3$ filler wire and the DP 600 steel. The centre line shifting could be fix with the correction of experimental setup.

\subsection{Microhardness measurement}

The microhardness profile of the MIG brazed joint of DP 600-DP 600 steels sheet are given in Fig. 6. The dotted lines show the basic materials hardness value in the Figures (Table 1).

The microhardness changing is symmetrical to the centre line, the same microstructure transformation happened in the DP 600 steels. The highest heat input region of the DP 600 steel has $344 \mathrm{HV}$. This hardness change suggests that, the original ferrite-martensite microstructure changed to bainite and the grain size growed. The HAZ (heat affected zone) of DP 600 starts $3 \mathrm{~mm}$ from the centre. The steel is softened to $190 \mathrm{HV}$ in the HAZ. This high degree of hardness changing could cause negatively effect on the tensile tests.

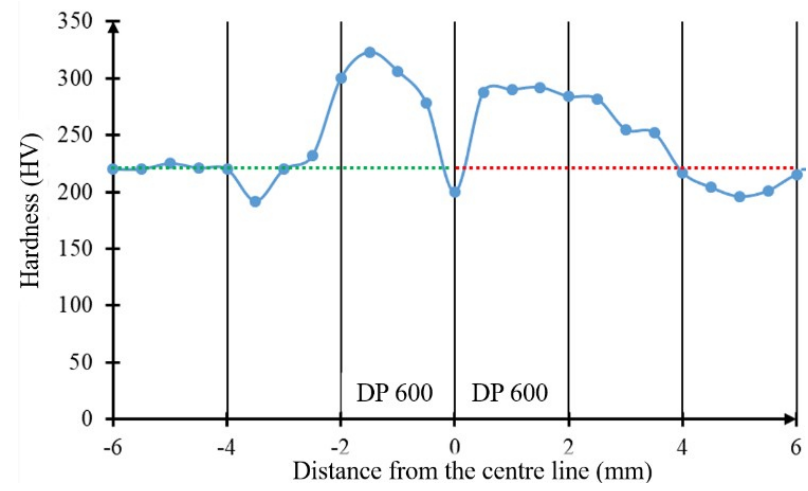

Fig. 6 Microhardness profile of the MIG brazed joint of DP 600-DP 600 steels
Fig. 7 shows the DC 01-DC 01 brazed joint microhardness profile.

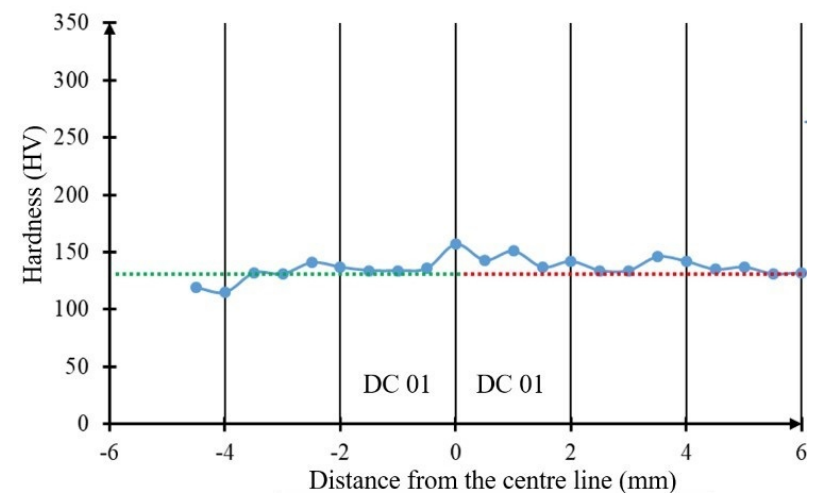

Fig. 7 Microhardness profile of the MIG brazed joint of DC 01-DC 01 steels

The hardness of the highest heat input region of the DC 01 steel has $150 \mathrm{HV}$. The DC steel microstructure contains only ferrite and cannot be quenched, because of the low level of carbon. The low increase of the hardness is caused by the grown of the grain size.

The microhardness profile of the hybrid DP 600-DC 01 joint is given in Fig. 8.

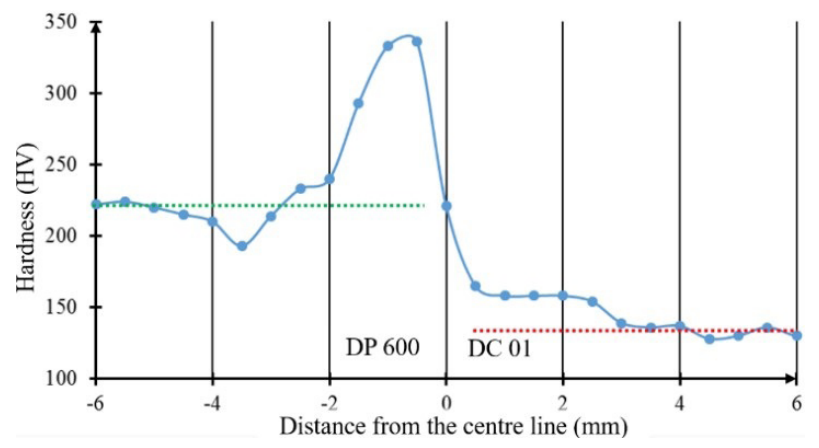

Fig. 8 Microhardness profile of the hybrid MIG brazed joint of DP 600-DC 01 steels

The same hardness changing occurred in the mixed DP-DC joint, what happened separately in DP-DP and DC-DC joints. The DC 01 steel has the lowest microhardness in the hybrid joint, it suggest that, it will fracture in the base material during the tensile test. The microhardness of the base materials are higher in the region where copper connect with the steels. It could be because of the high level of heat input and the copper could create solid solution with the base materials on this working temperature and 3-4\% of copper (Fig. 9). The CuSi3 filler wire melting point is $980^{\circ} \mathrm{C}$ and the MIG brazing working temperature is about $1100^{\circ} \mathrm{C}$. 


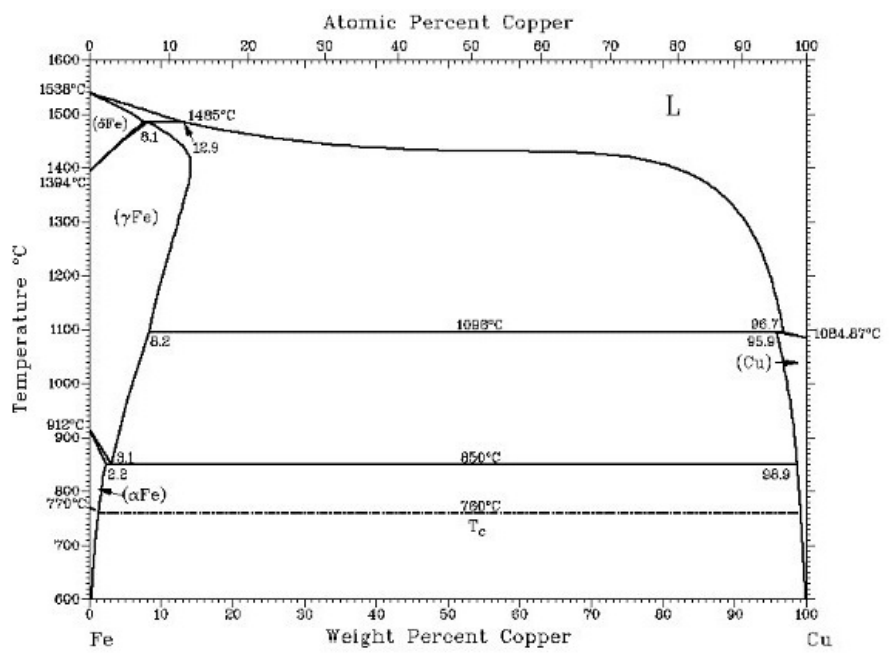

Fig. $9 \mathrm{Cu}$-Fe phase diagram (ASM)

\subsection{Tensile test}

The tensile strength of the examined joints can be seen in Fig. 10 .

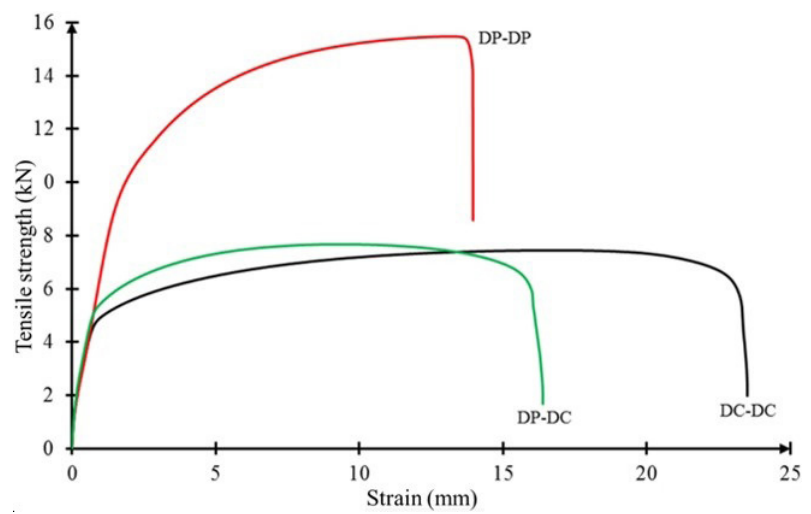

Fig. 10 Tensile strength of the examined brazing joints

The DP-DP steel pairing ultimate strength was the highest, $15500 \mathrm{~N}$. The strain of the specimen was low $14 \mathrm{~mm}$, because of the ferrite-martensite microstructure. The specimen broken near the heat affected zone -as expected -, because of the grain size and hardness changing (Fig. 11). Deformation can not be seen on the brazed joint.

The tensile strength of the DC-DC joints was the lowest $7500 \mathrm{~N}$, it's half of the DP-DP joint strength, but the strain much longer. The full ferrite microstructure has much strain. This characteristic is specific for the DC 01 steels.

The DC-DC specimen broke in the base material, far from the brazed joint (Fig. 12).

In case of the hybrid DP-DC joints were tested the maximum tensile strength limit of the specimens was the tensile strength of the DC 01 steel, $7500 \mathrm{~N}$. The strain is shorter, because only the DC steel has a good deformation property. In every case the DC 01 steels broken during the tensile tests far from the MIG brazed joints (Fig. 13). In every case when the DC 01 steel broken, the fractures were diagonally.

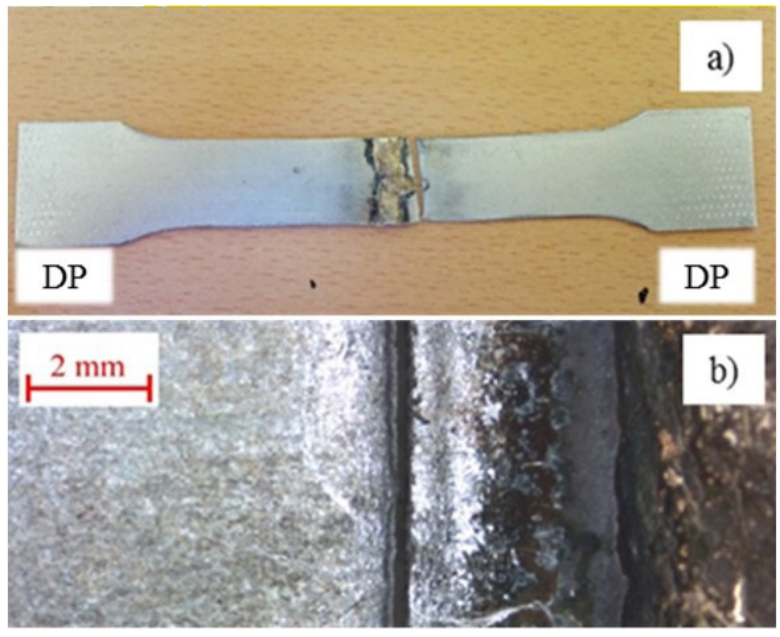

Fig. 11 DP 600-DP 600 tensile specimen broke near the HAZ

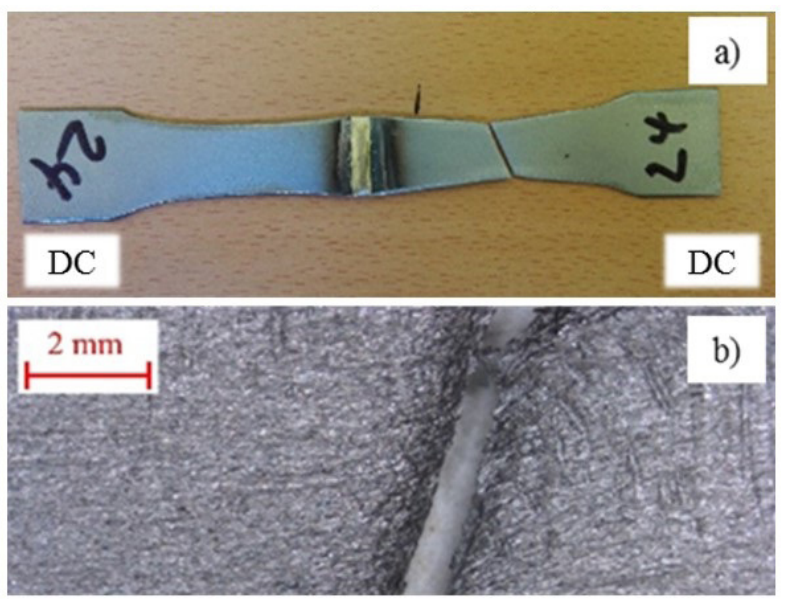

Fig. 12 DC 01-DC 01 tensile specimen broke in the base material
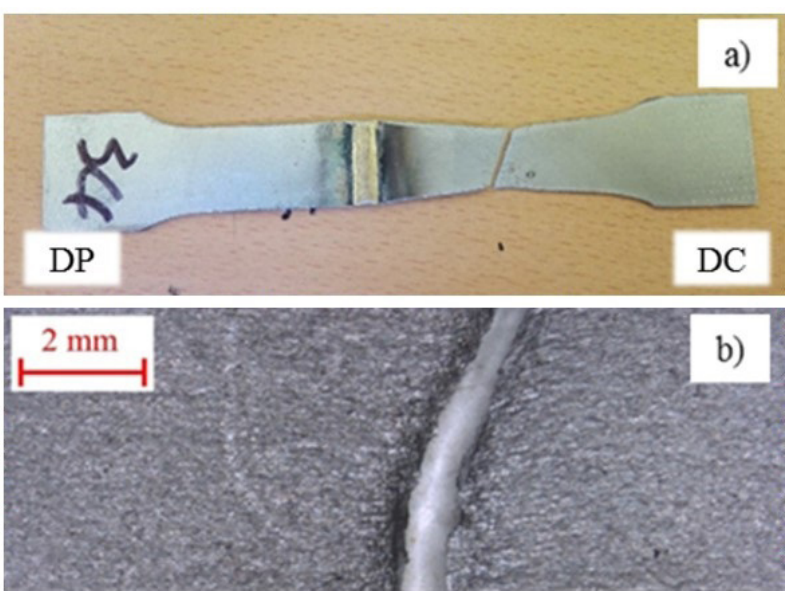

Fig. 13 Hybrid DP 600-DC 01 tensile specimen broke in the base material

\section{Conclusion}

Research goal was to produce a joint between DP 600 and DC 01 steel sheets using MIG brazing, the following conclusions can be drawn from this study:

The wettability of DP 600 and DC 01 was measured after the brazing method. We found that the $\mathrm{CuSi} 3$ brazing material 
wetting angle in solid state on the DP side is $60^{\circ}$, on the DC side is $30^{\circ}$.

The microhardness profile of the MIG brazed joint was measured and we found there is a maximum in the hardness curve in the border of the DP 600 steel and the CuSi3 brazing material. On the maximum the hardness is $125 \mathrm{HV}$ higher than the DP 600 base material. This effect can cause an embrittlement of the joint.

The DC 01 steel hardness is not changed significantly.

The tensile strength of the brazing joints was examined different steels composition. The results is accord to the expectation value, we got the highest tensile strength in the DP-DP composition.

\section{Acknowledgement}

The publication of the work reported herein has been supported by NTP-NFTÖ-17-B-0514, National Talent Programme, Ministry of Human Capacities, Human Capacities Grant Management Office (EMET).

This research is supported by EFOP-3.6.1-16-2016-00014 project. The Project is supported by the Hungarian Government and co-financed by the European Social Fund.

\section{References}

ASM International's Binary Alloy Phase Diagrams, (2017).

Budai, D., Tiszai, M. (2015). Development trends in aluminium car body produvtion. Material Engineering. 148(5), pp. 29-36.

Cardoso, M. C., Moreira, L. P. (2015). Forming Limit Analysis of DP600-800 steels. International Science Index, Materials and Metallurgical Engineering. 9(9), pp. 1123-1126.

Dezso, A., Kaptay, G. (2017). On the configurational entropy of nanoscale solutions for more accurate surface and bulk nano-thermodynamic calculations. Entropy. 19(6), pp. 248-259. https://doi.org/10.3390/e19060248

Ghosh, P., Ray, R. K. (2017). Deep drawable steels. In: Automotive Steels. Woodhead Publishing, pp. 113-143. https://doi.org/10.1016/B978-0-08-100638-2.00005-5

Hlinka, J., Weltsch, Z. (2013). Relation between the wetting property end electrical conduction of silver-gold (Ag-Au) alloys. Periodica Polytechnica Transportation Engineering. 41(2), pp. 95-98. https://doi.org/10.3311/PPtr.7108

Hlinka, J., Berczeli, M., Buza, G., Weltsch, Z. (2017). Wetting properties of Nd:YAG laser treated copper by solders. Soldering \& Surface Mount Technology. 29(2), pp. 69-74. https://doi.org/10.1108/SSMT-01-2016-0003

Joeri, R., David, L. M., Brian, C. O., Keywan, R. (2013). 2020 emissions levels required to limit warmint to below $2^{\circ} \mathrm{C}$. Nature Climate Change. 3, pp. 405-412. https://doi.org/10.1038/nclimate1758

Kalácska, E., Májlinger, K., Fábián, E. R., Pasquale, R. S. (2017). MIG-welding of dissimilar advanced high strength steel sheets. Materials Science Forum. 885, pp. 80-85. https://doi.org/10.4028/www.scientific.net/MSF.885.80
Malte, M., Nicolai, M., William, H., Sarah, R., Kajta, F., Reto, K., David, J. F., Myles, R. A. (2009). Greenhouse-gas emission targets for limiting global warming to $2^{\circ}$ C. Nature. $459(909)$, pp. 1158-1162. https://doi.org/10.1038/nature08017

Májlinger, K., Szabó, P. J., Bobor, K. (2013). Intercrystalline cracking of austenitic steel during brazing. Materials Science Forum. 729, pp. 442-447. https://doi.org/10.4028/www.scientific.net/MSF.729.442

Michael, L. (2007). Experimental investigations of the roll load and roll torque when high strength steel is roll formed. Journal of Materials Processing Technology. 191(1), pp. 44-47.

https://doi.org/10.1016/j.jmatprotec.2007.03.041

Oliver, S., Jones, T. B., Fourlaris, G. (2007). Dual phase versus TRIP strip steels: Microstructural changes as a consequence of quasi-static and dynamic tensile testing, Materials Characterization. 58(4), pp. 390-400. https://doi.org/10.1016/j.matchar.2006.07.004

Pickin, C. (2007). Cold metal transfer (CMT) brazing of galvanised steel sheets. [pdf]. Avaliable from: https://www2.warwick.ac.uk/fac/sci/wmg/ research/pard/pardprojects/advbodyjoin/results/rsw/pardp_pwi_for_ cmt.pdf [Accessed: 8th July 2017].

Sushovan, B., Tapan, K. P., Mahadev, S., Maity, J. (2013). GMA brazing of galvannealed intersitial free steel. Suplement to the Welding Journal. 92(1), pp. 29-35.

Sushovan, B., Tapan, K.P., Mahadev, S. (2016). High-cycle fatigue behavior of MIG brazed galvanized DP600 steel sheet joint-effect of process parameters. International Journal of Advanced Manufactirung and Technologies. 82, pp. 1197-121.

https://doi.org/10.1007/s00170-015-7451-1

Verezub, O., Kalazi, Z., Buza, G., Verezub, N. V., Kaptay, G. (2011). Classification of laser beam induced surface engineering technologies and in situ synthesis of steel matrix surface nanocomposites. Surface Engineering. 27(6), pp. 428-435. https://doi.org/10.1179/174329409X446296

Volvo 2012 S60 body structure. [image online]. Avaliable from: http://www. boronextrication.com/2011/08/16/2012-volvo-s60-body-structure/ [Accessed: 8th July 2017]. 